\title{
Blue Holes in Bahamas: Repositories of Climate, Anthropogenic, and Archaeological Changes over the Past 300000 Years
}

\author{
P K Swart*, M Arienzo \\ Marine Geology and Geophysics, University of Miami, 4600 Rickenbacker Causeway, Miami Fl 33149, USA \\ K Broad \\ Marine Affairs and Policy, University of Miami, 4600 Rickenbacker Causeway, Miami Fl 33149, USA \\ A Clement \\ Meteorology and Physical Oceanography, University of Miami, 4600 Rickenbacker Causeway, Miami Fl 33149, USA \\ B Kakuk \\ Bahamas Underground, March Harbour Bahamas
}

Blues Holes in the Bahamas are solution collapse features which formed in the Bahamas during the repeated sea-level changes which have occurred over the past 2 million years. Not only were these Blue Holes repositories of well preserved organisms which found their ways into their anoxic waters and therefore have been very well preserved, but the sediments also record a legacy of anthropogenic activities in the area during the Pleistocene. Perhaps the most intriguing aspects of the Blue Holes are the multiple generations of stalagmites which record variations in sea-level, temperature, and precipitation during the numerous sea-level low stands. During these periods the caves were located within the vadose zone and freshwater leached the overlying carbonate. As the waters trickled into the caves

This study was supported by the National Geographic Magazine, and the Stable Isotope Laboratory.

*Corresponding author: pswart@rsmas.miami.edu

(C) China University of Geosciences and Springer-Verlag Berlin Heidelberg 2010

Manuscript received December 22, 2009.

Manuscript accepted March 10, 2010. they rapidly degassed forming both stalactites and stalagmites. Using uranium series dating these materials have been accurately dated and the variations in the stable isotopes and trace elements analyzed. These analyses reveal three periods of speleothem formation, 14 000-60 000, 200 000-250 000, and 300000 350 000. Analyses to date reveal that all the Heinrich events evident in the deep-sea sediments are present in the Bahamian stalagmites as rapid changes in the stable $\mathrm{C}$ and $\mathrm{O}$ isotopic composition. The terminations of the Heinrich event can be interpreted as reflecting changes from relative dry to wet conditions, a change which occurred over periods as short as 50 years. Also associated with each Heinrich event is a prolonged period of elevated $\mathrm{Fe}$ concentration. As there are no indigenous sources of $\mathrm{Fe}$ in the Bahamas, the Fe believed to be ultimately derived from Saharan dust. The $\mathrm{Fe}$ is dissolved in rain water as the dust is washed through the permeable rock and is co-precipitated with the calcite in the stalagmite. Clearly during the Heinrich event, Sahel region of Africa was significantly drier than normal and large amounts of atmospheric dust may have significantly impacted climate. 